\title{
Mapping Flash Flood Potential and Risk Level Using GIS Techniques and the Flash Flood Potential Index (FFPI) in Amman Zarqa Basin of Jordan
}

\author{
Moayyad Shawaqfah'), Fares AlMomani' ${ }^{2)}$ and Ahmed Khatatbeh ${ }^{1)}$ \\ ${ }^{1)}$ Department of Civil Engineering, Al al-Bayt University, Mafraq, 25113 Jordan \\ ${ }^{2}$ Department of Chemical Engineering, College of Engineering, Qatar University, Doha, Qatar
}

\begin{abstract}
Jordan is located in an arid and semi-arid climatic zone, where about $80 \%$ of the country, known as the "Badia". Generally, this is classified as a dry or arid region. Climate change is expected to exacerbate the current aridity and scarcity of water resources in Jordan. Sudden and extreme weather events are becoming more common; this likely means longer and drier summers, more severe droughts, harsher winters, and an increase in flash floods. Jordanian Civil Defense reported that during 1963-2019, 451 people were killed and about one million people affected by flash floods. This research aims to determine the critical locations of flash floods in the Amman Zarqa Basin. This research methodology depends on using four variables (slope, vegetation cover/density, soil type/texture, and land use/cover) under the GIS environment to calculate the Flash Flood Potential Index (FFPI). This index has not been used in Jordan (up to our knowledge). Five scenarios were used in this study, based on previous reviews and the last one (scenario 5) based on Jordanian experts of flash floods in Jordan. The results show that increasing the weight of slope and land use in different FFPI equations will increase the values of FFPI. Reducing the vegetation density by $50 \%$ resulted in limited effects on the importance of FFPI. The risk level is divided into four categories (extreme, high, medium, and low) related to the FFPI values. Scenario two, which uses equal weights for all parameters, had the lowest risk level all over the area. Scenario four, which double the consequences of the slope and the land use with respect to the other two parameters. This has the highest risk level over the study area. Based on equation no. 5, which is modified based on Jordanian experts' opinion, the low-risk level covered $9.01 \%$ of the basin. Besides, the medium, high, and extreme risk levels covered $72.96 \%, 15.89 \%$, and $2.14 \%$ of the study area, respectively.
\end{abstract}

Keywords: flash floods, FFPI, climate change, risk level, Jordan

\section{Introduction}

Climate change is among the worldwide natural phenomena that have received the most consideration in different life domains. In 2014 IPCC reported an increase in the extreme precipitation events in various locations globally, which implies high flood risks. The flash flood due to climate change impact that creates a negative effect on human and natural systems. These phenomena are becoming more frequent and have detrimental environmental, economic, political, and security implications. Thus, researchers assessed flash flood exposure and vulnerability in areas around the world (White (1975), Tobin (1986), Hughey (2006), Ruin et al., (2008), Fuchs (2009), Creutin et al. (2013), Almomani and Shawaqfah (2013), Spitalar et al. (2014), Fuchs et al., ( 2015), Terti et al., (2015), Karagiorgos et al., ( 2016a, 2016b). The American Meteorological Society (AMS (2000) defined the flash flood as "A flood that rises and falls quite rapidly with little or no warning, usually as the result of intense rainfall over a relatively small area" (AMS, 2000). Hydrologists and experienced forecasters are aware of areas that are most prone to flash flooding. Still, precisely these areas are and which sites are the most vulnerable have often not been studied in detail or adequately documented. Creating a "Flash Flood Potential Index (FFPI)" will, therefore, help to represent how "flashy" the land is in certain areas. An index such as this will significantly improve the flash flood warning accuracy. Smith (2003) was the first researcher who developed an FFPI for the Colorado River basin by considering four factors: slope, vegetation cover/density, soil texture, and land use. Additional FFPI studies were carried out by (Kruzdlo (2010), Ceru (2012), Zogg and Deitsch (2013), Arachchige and Perera (2015), Teodor and Matreata (2011), Zaharia et al. (2012), Minea (2013), and Pravalie and Costache (2014)). This investigation utilizes the FFPI model to recognize zones with high flash flood likely dependent on an assessment of physiographic factors controlling the development of flash floods in the Amman Zarqa Basin (AZB). The original FFPI equation was developed by Smith (2003) using equation (1). This investigation utilizes the FFPI model to recognize zones with high flash flood likely dependent on an assessment of physiographic factors controlling the development of flash floods in the Amman Zarqa Basin (AZB).

Received on February 12, 2020; accepted on November 13, 2020; correspondence concerning this article should be addressed to Moayyad Shawaqfah (Eemail address: mshawaqfah@aabu.edu.jo). ORCiD ID for Moayyad Shawaqfah https://orcid.org/0000-0001-6766-4504 
The original FFPI equation was developed by Smith (2003) using equation (1). Each input parameter has a scale from 1-10, divided by the sum of weightings $(\mathrm{N})$ to determine the overall FFPI between $1-10$.

$$
\text { FFPI }=\frac{(n(M)+L+S+V)}{N}
$$

Where $n$ is the slope layer weight (>1), $M$ is the land Slope, $L$ is Land Cover/Use, $S$ is Soil Type/Texture, $N$ is the sum of weightings (With $L=S=V=1.0$ and $M>1.0$ ). In 2009 Brewster modified the original FFPI (Smith (2003)) for application in Binghamton, NY. The modified FFPI provided more considerable weight to the slope and less weight to the vegetation cover than the land use and soil type, indicating a high potential for flash flood in the areas with the highest slope (equation 2).

$$
F F P I=\frac{(1.5(M)+L+S+0.5(V))}{4}
$$

In 2010, Kruzdlo, used an equal weighting pattern for equation (1) and applied FFPI for State College, Pennsylvania.

$$
F F P I=\frac{(M+L+S+V)}{4}
$$

Ceru (2012) modified equation (3) by giving extra weight to the slope and land use/cover based on hydrologists consultant advice from the Mid Atlantic River Forecast Center (equation (4)).

$$
F F P I=\frac{(M+L+S+V)}{N}
$$

Where $N=$ Number of input variables, ( $S$ and $V$ are given weights of $1, N$ is greater than 4 , as the slope and land use/cover were given a value greater than 1 . These four equations describe the flash flood potential index quantitatively based on the study area (slope, land cover/use, and soil type/texture and vegetation). They, therefore, can be used to identify flash flood-prone locations. In 2013, Zogg and Deitsch used various weights for the physiographic parameter to acquire the best outcomes. Their study shows that the most significant slope zones will be represented better when using the slope in percent than using gradient degrees.

\section{Material and Methods 1.1 Study Area}

The study area is shown in Figure 1 (Amman Zarqa Basin or AZB) of $3918 \mathrm{~km}^{2}$ lies between the lines of Jordan, JTM (Jordan Transverse Mercator). Coordinates E370 and E470, N525 and N585 (89\% is located in Jordan and $11 \%$ inside Syria). The largest axis of the basin $(116 \mathrm{~km})$ extends from north northeast to south-southwest, and its perpendicular axis is about $67 \mathrm{~km}$.

\subsubsection{Topography}

The topography in the basin changes from west to east, where the hilly areas comprise a large part of the western and the surrounding regions along the basin's boundary. Altitude gradually decreases towards the center of the basin and the Jordan Valley's catchment outlet near Deir Allah in the west (AlMahamid, 2005). From the center of the catchment, the altitudes increase towards the northeast into Syria. The highest point of the catchment (1570 $\mathrm{m}$ above mean sea level (a.m.s.1.)) in Jabel El-Arab/Jabel El-Druz is located north of Salkhad town Syria. The lowest point in the catchment is about $140 \mathrm{~m}$ below mean sea level (b.m.s.l) near Deir Allah town in Jordan

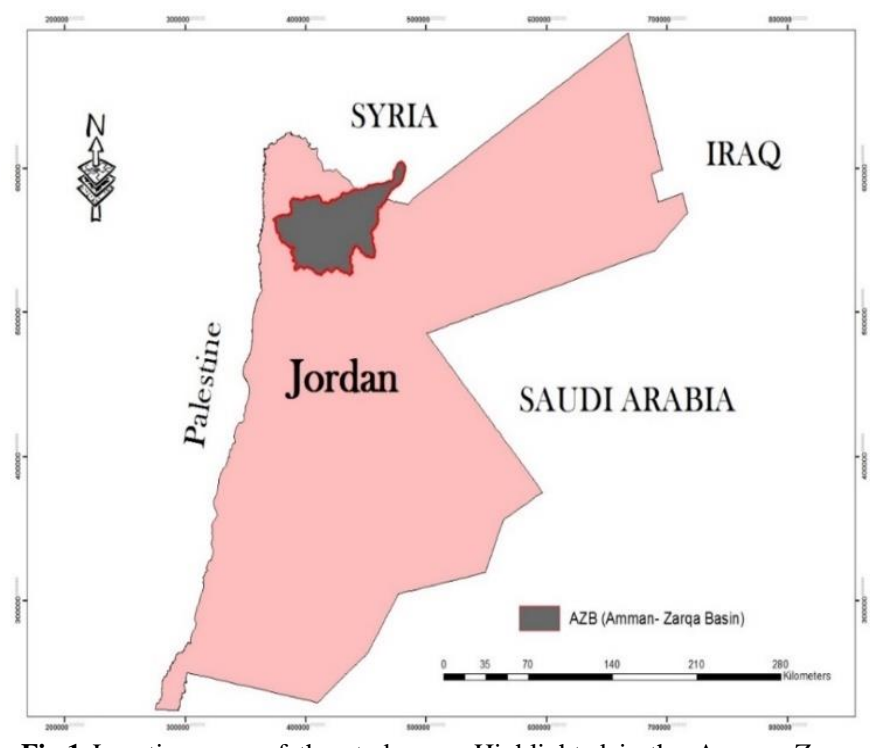

Fig.1 Location map of the study area Highlighted is the Amman-Zarqa Basin (AZB).

(Figure2). The whole catchment's general slope is relatively high, although the central and eastern part is almost flat plateaus surrounded by hills from the west and south, which have the highest gradients. The slopes of the mountains are modest in most of the catchment area. The slopes do not exceed $15 \%$ and are mostly well below 5\%. Gradients of $15 \%$ to $30 \%$ are standard in the western part (lower part) of the catchment. Steep slopes that exceed 30\% occur only in hilly places in parts of the west of northwestern highlands, and in some cliffs, along wadis, the slopes reach 70\%. In the eastern part of the catchment near Qasr Al-Hallabat, there is a 
mudflat of about $500 \mathrm{~km}^{2}$.

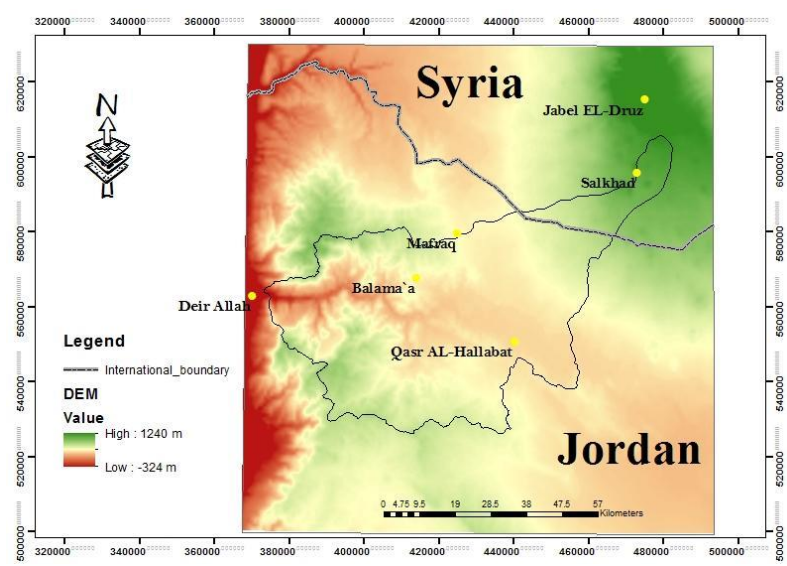

Fig. 2 DEM of Amman-Zarqa Basin (AZB)

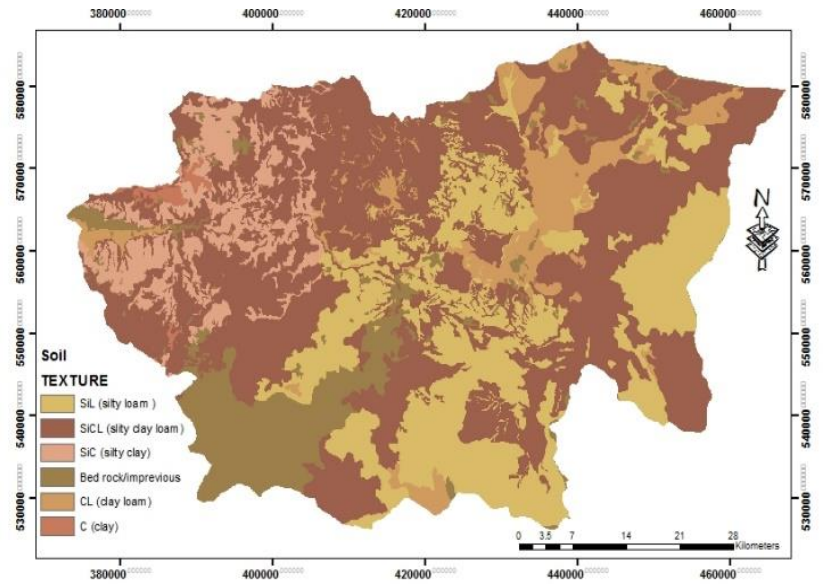

Fig. 3 Soil Texture of Amman- Zarqa Basin (Hammori et al., 2015).

Soil Texture at a particular location can be determined based on different parameters (temperature, water flow, vegetation cover, land use, solar radiation, rock type, and wind). AZB soil texture can be subdivided into five soil groups depending on the soil texture (Figure 3).

\subsubsection{Climate}

Climatologically, Jordan belongs to the Mediterranean region, described as a dry season (May to September) with relatively high temperatures and a rainy season of lower temperatures in the remaining part of the year. Sometimes have moderate frosty nights and some snowfalls for few days over the highlands (Al Mahamed, 2005). Typically, cold and warm weather fronts and low-pressure depressions move from west-southwest to east-northeast in the southern Mediterranean area during the winter. The cold and warm fronts are steered by depressions that occur over Cyprus and reach Jordan in a southwesterly to northeasterly direction. Also, the orographic effect causes rainfalls in Jordan Valley (western and eastern parts). Thunderstorms of intensive precipitation could occur in the warm months of April, May, and October. In the summertime, no determined air-mass movements affect the region's weather, and no precipitation occurs. From west to east of Jordan, the topography plays the primary role in changing the rainfall and temperature. Rain because of the orographic effect and temperature with the altitude and wind speeds. Evaporation and evapotranspiration are affected by altitude, wind speed, humidity, soil moisture, and canopy cover.

\subsubsection{Land use}

The land use of AZB comprises $65 \%$ bare rock, including urbanized areas, and 35\% natural crops, field crops, and trees (Figure 4). More than $90 \%$ of the agricultural activities $(25.27 \%$ from the total area) are located in the western and north-eastern parts of AZB. According to the land-use, which is created based on Landsat imagery. Using High-resolution images (Landsat 8) was downloaded from the website (http://earthexplorer.usgs.gov/). After that, the multi-band raster imagery converted to a single-band raster with several categorical land use classes using the supervised classification method, based on the personal user experience. The land use of AZB varies from urban, bare soil, bare rocks, field crops, and Trees; based on the satellite imagery, the total amount of irrigated land is about $17 \mathrm{~km}^{2}$. The vegetation density map (IUCN, (2015)) was used to assess the FFPI (Figure 5).

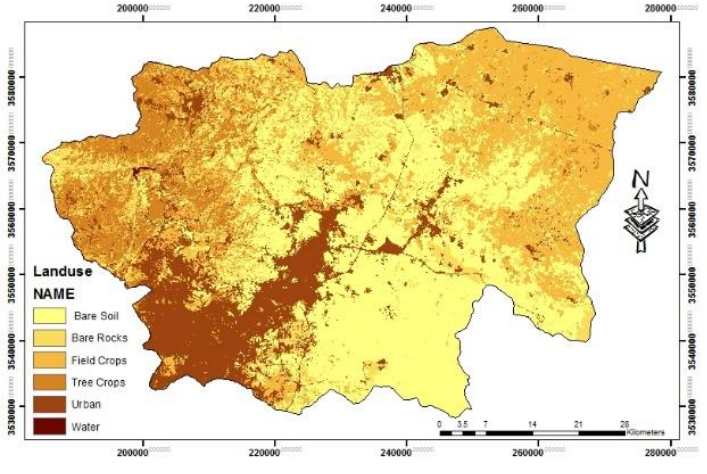

Fig. 4 Land use of the study area. 


\subsection{Flash Flooding in the Study Area}

Flash flood events are growing worldwide, with more disastrous impacts than any other time in recent memory. In the regional countries, the synergy of natural disasters, fast urbanization, scarcity of water, and climate change has developed as a severe challenge to decision-makers. Historically, Jordan was affected several times by flood disasters. Recently disasters related to flash floods, landslides, and droughts are becoming more frequent. Although there is no scientific relation is given to prove this phenomenon, but research is still undergoing. These kinds of disasters have caused losses in life and cost millions of economic damages in different parts of the country. Table $\mathbf{1}$ presents a summary of the major floods and storms in Jordan since 1963. Jordanian Civil Defense Records shows that during the most recent three decades, flash floods brought about the 451 death. There are fifteen surface water basins in Jordan. Most wadis in AZB are characterized by seasonal flow in the form of flash floods. In addition, there are two rivers (perennial flow), namely

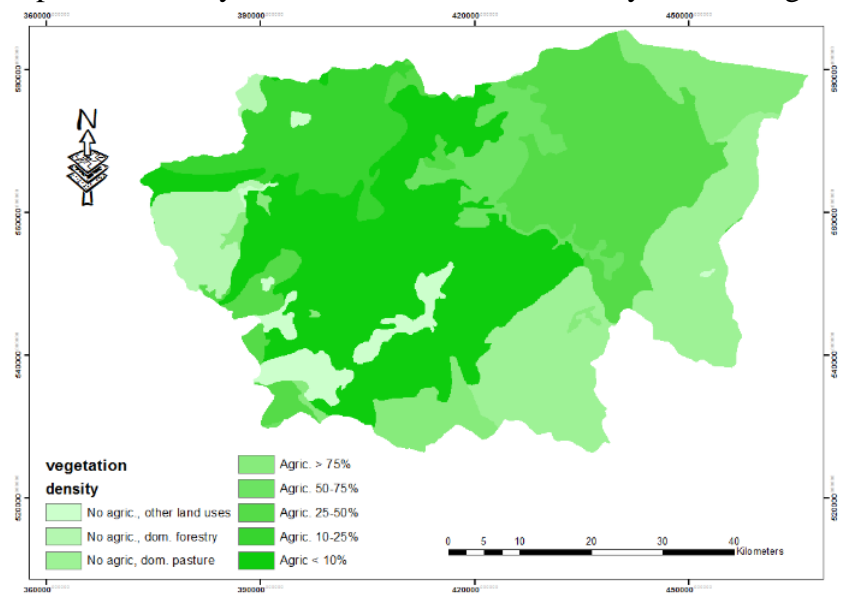

Fig. 5 Vegetation Density in the study area (IUCN, 2015)

Yarmouk and Jordan River.

There are eight flood gages in the study area; the first was installed in 1963 on the Zarqa River on the Jerash Bridge (AL0060). Eight gauging floods (Figure 6) were installed in the next decade (AL0040, AL0061, AL0062, AL0063, AL0064, AL0065), and the last one was installed in 2002 (AL0070). The analysis of flood events recorded by the above flood gages showed that between 1.6 and 8.1 (average 3.98) runoff events per year occur across the basins (MWI, 2012). The average number of incidents at each flood station in the study area is given in Table 2.

Table 1 Major floods and storms in Jordan since 1963 (compiled from EM-DAT Database and Jordan Civil Defense Statistics).

\begin{tabular}{|c|c|c|c|c|c|c|c|}
\hline Disaster & Date & Killed & Affected & Disaster & Date & Killed & Affected \\
\hline Flood & 1963 & 25 & No Data & Flood & 2009 & 6 & 265 \\
\hline Flood & 1964 & 6 & No Data & Flood & 2010 & 7 & 522 \\
\hline Flood & 1966 & 259 & No Data & Flood & 2011 & 7 & 132 \\
\hline Flood & 1987 & 9 & 29 & Flood & 2012 & 6 & 491 \\
\hline Flood & 1991 & 11 & 18,000 & Flood & 2013 & 0 & 2214 \\
\hline Flood & 1997 & 2 & No Data & Flood & 2014 & 0 & 540 \\
\hline Storm & 2000 & 9 & 200 & Flood & 2015 & 4 & 300,000 \\
\hline Storm & 2002 & 5 & 125 & Flood & 2016 & 3 & 200,000 \\
\hline Flood & 2007 & 9 & 169 & Flood & 2018 & 35 & 150,000 \\
\hline Flood & 2008 & 6 & 185 & Flood & 2019 & 42 & 200,000 \\
\hline
\end{tabular}

Table 2. Analysis of the average number of incidents at each station (MWI, 2012)

\begin{tabular}{|c|c|c|c|c|c|}
\hline Stations & Station name & $\begin{array}{c}\text { Catchment } \\
\left(\mathbf{k m}^{2}\right)\end{array}$ & $\begin{array}{c}\text { Number of } \\
\text { incidents }\end{array}$ & $\begin{array}{c}\text { Number of } \\
\text { years }\end{array}$ & $\begin{array}{c}\text { Avg. events/ } \\
\text { Year }\end{array}$ \\
\hline AL0040 & Wadi Um al Dananeer & 37.1 & 180 & 43 & 4.2 \\
\hline AL0060 & Zarqa at New Jerash Bridge & 3554.3 & 373 & 46 & 8.1 \\
\hline AL0061 & Wadi Sleihi & 38.0 & 228 & 46 & 5.0 \\
\hline AL0062 & Ain Ghazal & 155.7 & 67 & 16 & 4.2 \\
\hline AL0063 & Wadi Zarqa at Sukhne & 642.8 & 110 & 30 & 3.7 \\
\hline AL0064 & Wadi Dhuleil at Sukhne & 2375.0 & 40 & 17 & 2.4 \\
\hline AL0065 & Wadi Abdoun & 75.9 & 68 & 26 & 2.6 \\
\hline AL0070 & Wadi Zatari & 421.6 & 14 & 9 & 1.6 \\
\hline
\end{tabular}




\subsection{Data and Methods}

This study's required data sets collected from different sources (Table 3) shows an example where data were collected. Reclassification of raster maps, each of the four physiographic parameters obtained in the form of thematic raster layer was then reclassified into 10 classes based on their hydrological response of the watershed to flash flood generation with the help of using ArcGIS 10.2 (ESRI (2011)). Class 1 being the least favorable for flash flooding, and class 10 being the most promising for flash flooding. The FFPI values for the attributes of each parameter are shown in Table 4. All thematic maps of the four parameters were indexed to FFPI, as shown in Figures 7. After reclassifying all the data sets, the Raster Calculator in ArcGIS was used to perform the map algebra operations to calculate FFPI in the study area. This primary step's purpose was to average the layers together to construct

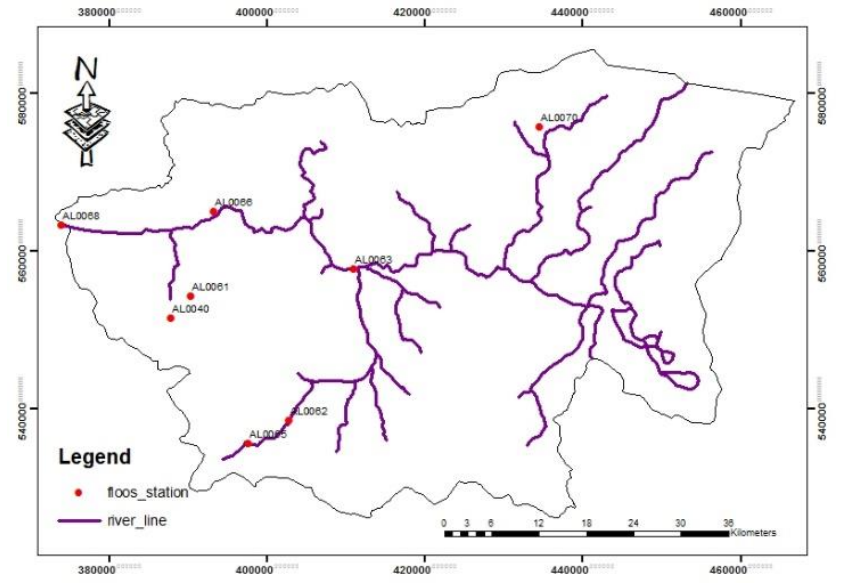

Fig. 6 Gauging Floods in AZB.

Table 3 Data Resources for Amman Zarqa Basin.

\begin{tabular}{|c|c|c|c|}
\hline & Data set & Resolution & Source \\
\hline 1 & Digital Elevation Model & $30 \mathrm{~m}$ & The CGIAR Consortium for Spatial Information (CGAIR-CSI) (http://srtm.csi.cgiar.org/). \\
\hline 2 & Soil Data & $1: 50,000$ & Ministry of Agriculture \\
\hline 3 & Land use/cover & $1: 50,000$ & Generated from Landsat 8, 2019 \\
\hline 4 & Vegetation Cover/Density & $1: 50,000$ & IUCN, 2015 \\
\hline
\end{tabular}

Table 4 Assigned FFPI values on each dataset depending on the susceptibility for flash flooding (Smith (2003), Brewster (2004), Kruzdl (2010), Smith (2010), Zogg and Deitsch (2013), and Minea (2013)).

\begin{tabular}{cllll}
\hline $\begin{array}{c}\text { FFPI } \\
\text { value }\end{array}$ & $\begin{array}{l}\text { Slope/DEM } \\
\text { (Slope\%) }\end{array}$ & \multicolumn{1}{c}{ Land Use } & $\begin{array}{r}\text { Vegetation } \\
\text { Cover }(\boldsymbol{\%})\end{array}$ & Soil Type \\
\hline $\mathbf{1}$ & 3 and below & Water & $90-100$ & Water/Alluvial \\
$\mathbf{2}$ & 6 & Woody Wetlands, Herbaceous Wetland & $80-89$ & Sand \\
$\mathbf{3}$ & 9 & Evergreen Forest & $70-79$ & Sandy Loam \\
$\mathbf{4}$ & 12 & Mixed Forest & $60-69$ & Silty Loam, Loamy sand \\
$\mathbf{5}$ & 15 & Deciduous Forest & $50-59$ & Silt/ Organic Matter \\
$\mathbf{6}$ & 18 & Pasture Hay, Cultivated & $40-49$ & Loam \\
$\mathbf{7}$ & 21 & Developed/open space, Barren Land & $30-39$ & Sandy Clay Loam, Silty Clay Loam \\
$\mathbf{8}$ & 24 & Developed/low & $20-29$ & Clay Loam, Sandy, Clay \\
$\mathbf{9}$ & 27 & Developed/medium & $10-19$ & Clay \\
$\mathbf{1 0}$ & 30 and above & Developed/heavy & $0-9$ & Bed, Rock/Impervious \\
\hline
\end{tabular}




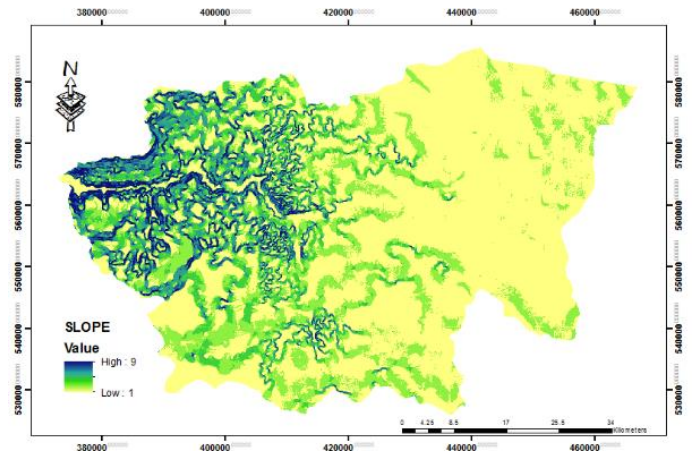

Reclassified slope map of the study area.

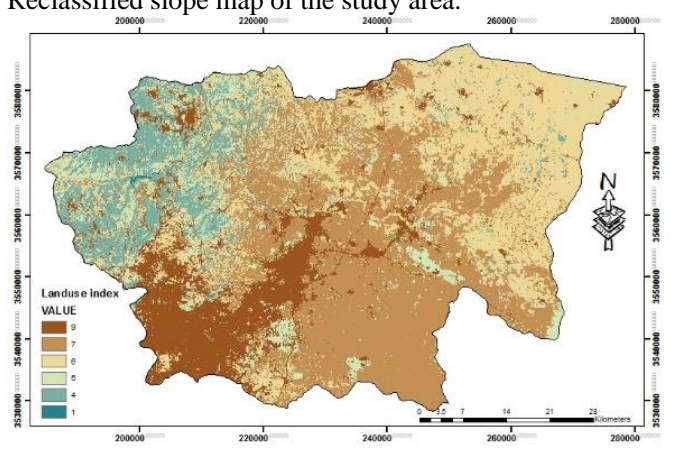

Reclassified land use map of the study area

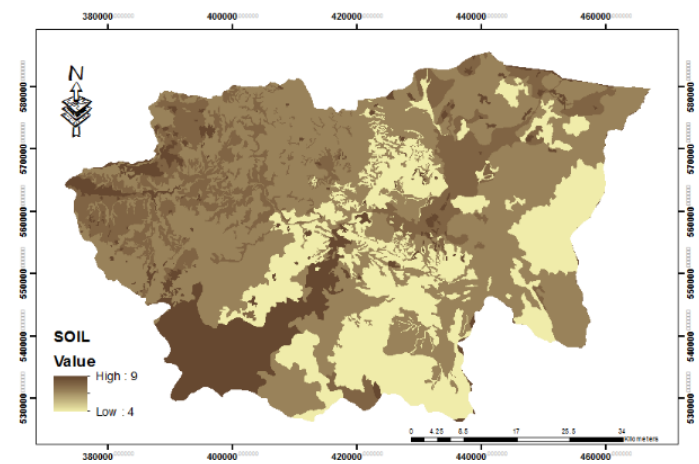

Reclassified soil type map of the study area.

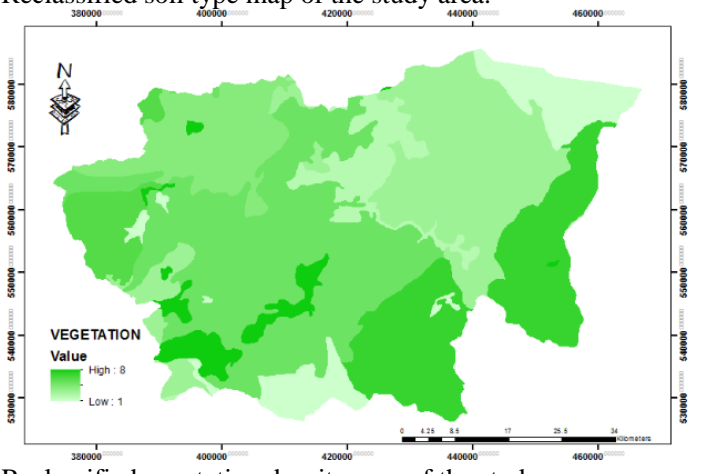

Reclassified vegetation density map of the study area

Fig.7. Reclassified maps (slope, soil, land use, and vegetation density).

\subsection{Analysis.}

The FFPI analysis was prepared based on five different scenarios. Each scenario used different equations (Table 5). Scenario 5 used a weighted formula. The Analytical Hierarchy Process (AHP), which was introduced by Saaty in 1980, is a popular and extensively used method for multi-criteria decision making. The AHP approach allows the use of qualitative, in addition to the quantitative criteria in evaluation. Both qualitative and quantitative information was compared using Jordanian experts' informed judgments of flash floods to derive each criterion's weights. The Jordanian experts were from 7 Jordanian University, two from the Ministry of Water and Irrigation, two from Jordanian Civil Defense, and two from the Jordanian Metrological Department. By using the AHP process, equation (5) was produced.

$$
\left[\left(M^{*} 1.5\right)+\left(L^{*} 1.32\right)+\left(S^{*} 1.16\right)+\left(V^{*} 1.02\right)\right] / 5
$$

Table 5 Equations used for FFPI scenarios

\begin{tabular}{clll}
\hline Scenario & Equation used & Parameters used & Notes \\
\hline 1 & $(1.5 M+L+S+V) / 4.5$ & Slope, land use, soil, vegetation cover & Smith (2003) \\
2 & $(M+L+S+V) / 4$ & Slope, land use, soil, vegetation cover & Kruzdlo (2010) \\
3 & $(1.5(M)+L+S+0.5(V)) / 4$ & Slope, land use, soil, vegetation cover & Brewster (2009) \\
4 & $(2(M)+2(L)+S+V) / 6$ & Slope, land use, soil, vegetation cover & Crue (2012) \\
5 & {$\left[\left(M^{*} 1.5\right)+\left(L^{*} 1.32\right)+\left(S^{*} 1.16\right)+\left(V^{*} 1.02\right)\right] / 5$} & Slope, land use, soil, vegetation cover & Jordanian Experts (AHP approach)
\end{tabular}




\section{Results and Discussion}

Applying the methodology described in section 1.3, the spatial representation of each scenario's FFPI values were obtained (Figures 9 through 13). Table 6 shows the percentage of area for each FFPI in each method.
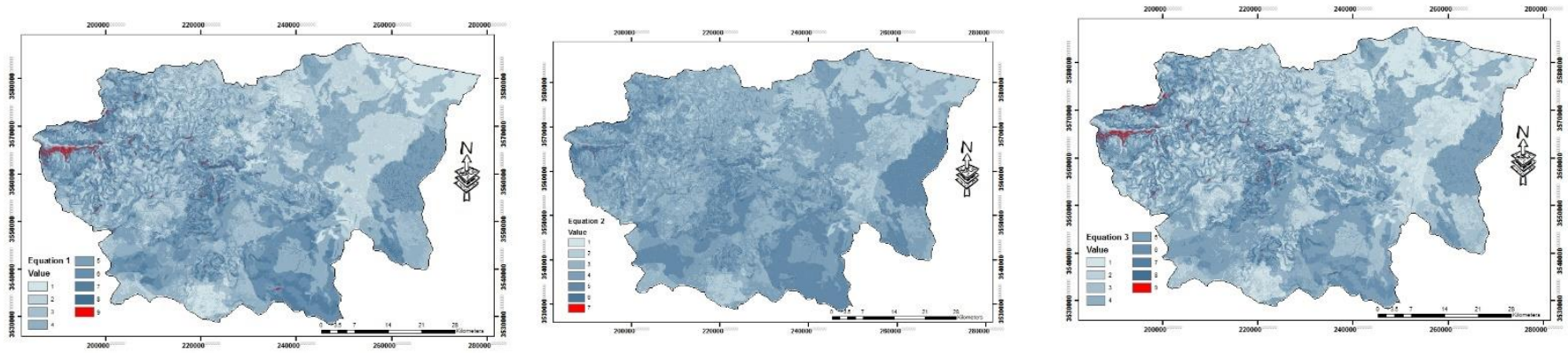

Fig. 9 FFPI of Amman Zarqa Basin-scenario 1. Fig.10 FFPI of Amman Zarqa Basin - scenario 2. Fig. 11 FFPI of Amman Zarqa Basin - scenario 3

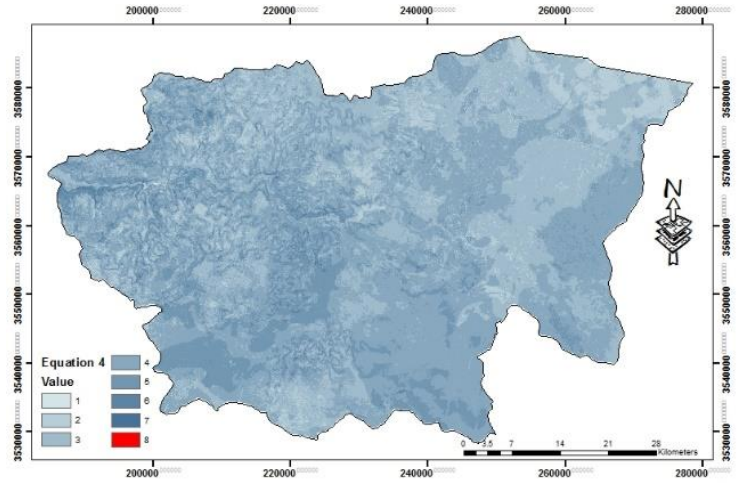

Fig. 12 FFPI of Amman Zarqa Basin - scenario 4.

Concerning Scenario 1, which is based on Smith's (2003) original equation, the study area's FFPI values range between 1 and 9 (Fig. 9). The highest values of FFPI are concentrated in the northwestern part of the study area and in Amman city (the capital of Jordan). This is because these areas are more steeply sloped, and the slope is weighted $50 \%$ higher than the other parameters in this scenario by $50 \%$. On the other hand, in about $73.27 \%$ of the study area, the FFPI values ranged between 2 and 5 , reflecting the area's relative flatness. In Scenario 2, the FFPI values range between 1 and 7 (Fig. 10). The highest FFPI values are found in Amman city because this area is heavily developed. Most of the area (59.52\%) has FFPI values ranging between 3 and 6 .

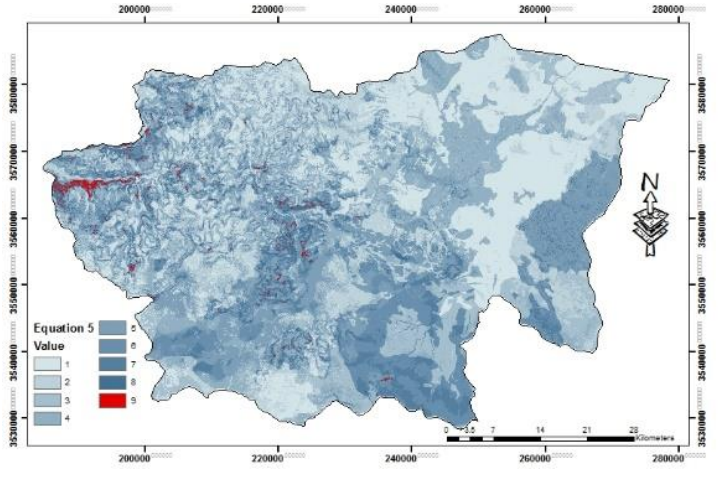

Fig. 13 FFPI of Amman Zarqa Basin - scenario 5.

Table 6 FFPI scenarios.

\begin{tabular}{cccccc}
\hline FFPI & \multicolumn{5}{c}{ Percentage of Area belong to different FFPI values(\%) } \\
& Equation 1 & Equation 2 & Equation 3 & Equation 4 & Equation 5 \\
\hline 1 & 6.93 & 0.08 & 13.70 & 0.00 & 20.89 \\
2 & 17.07 & 19.61 & 16.01 & 23.26 & 14.25 \\
3 & 16.52 & 15.88 & 14.63 & 24.08 & 16.36 \\
4 & 20.96 & 19.29 & 17.80 & 22.71 & 15.73 \\
5 & 18.73 & 24.36 & 23.09 & 24.60 & 13.87 \\
6 & 12.36 & 20.62 & 9.77 & 2.55 & 11.56 \\
7 & 5.51 & 0.17 & 3.47 & 2.58 & 5.24 \\
8 & 1.58 & 0.00 & 1.20 & 0.20 & 1.65 \\
9 & 0.35 & 0.00 & 0.33 & 0.00 & 0.45 \\
10 & 0.00 & 0.00 & 0.00 & 0.00 & 0.00 \\
\hline
\end{tabular}

The FFPI values in Scenario 3 range between 1 and 9 (Fig. 11). In this scenario, vegetation density was weighted lower (0.5) instead of one. Again, the highest FFPI values are in Amman city. About $55.51 \%$ of the study area has FFPI values ranging between 3 and 5. These results are like scenario 1, which indicates that vegetation's effect was weak in calculating the FFPI in AZB. 
In Scenario 4, the weight of slope and land use was doubled. The results show that $94.66 \%$ of the study area has FFPI values between 2 and 5 FFPI values. The maximum and minimum values of FFPI are 9 and 1, respectively (Fig. 12). The last scenario (Eqn.(5)), which depended on the Jordanian expert's opinion, showed the more effective flash flood mapping in the study area (Fig. 13). About $50.55 \%$ of the study area had an FFPI value between 3 and 5. The most highly ranked FFPI areas are located at the northwest of AZB. The results of each scenario were categorized into one of four classes based on FFPI values using the following equal interval classification to determine the risk level (Zogg and Deitsch 2013):

- Low $=<2.5 \quad$ Medium=Between 2.5-5

\section{- $\quad$ High=Between5-7.5}

- $\quad$ Extreme $=>7.5$

Scenario 5 had the most significant percentage of area related to an extreme and high level of risk as shown in Table 7, the main reason behind that the increased weight of slope and land use used in equation 5 . On the other hand, equation (2) had $88.72 \%$ of the total area with a medium risk level. Figure 14 shows the risk level map for each scenario compared with the historical risk level map for flash floods produced by IUCN in 2019. Scenario 5 is the most comparable with the historical flash flood in AZB, as shown in Fig. 14.
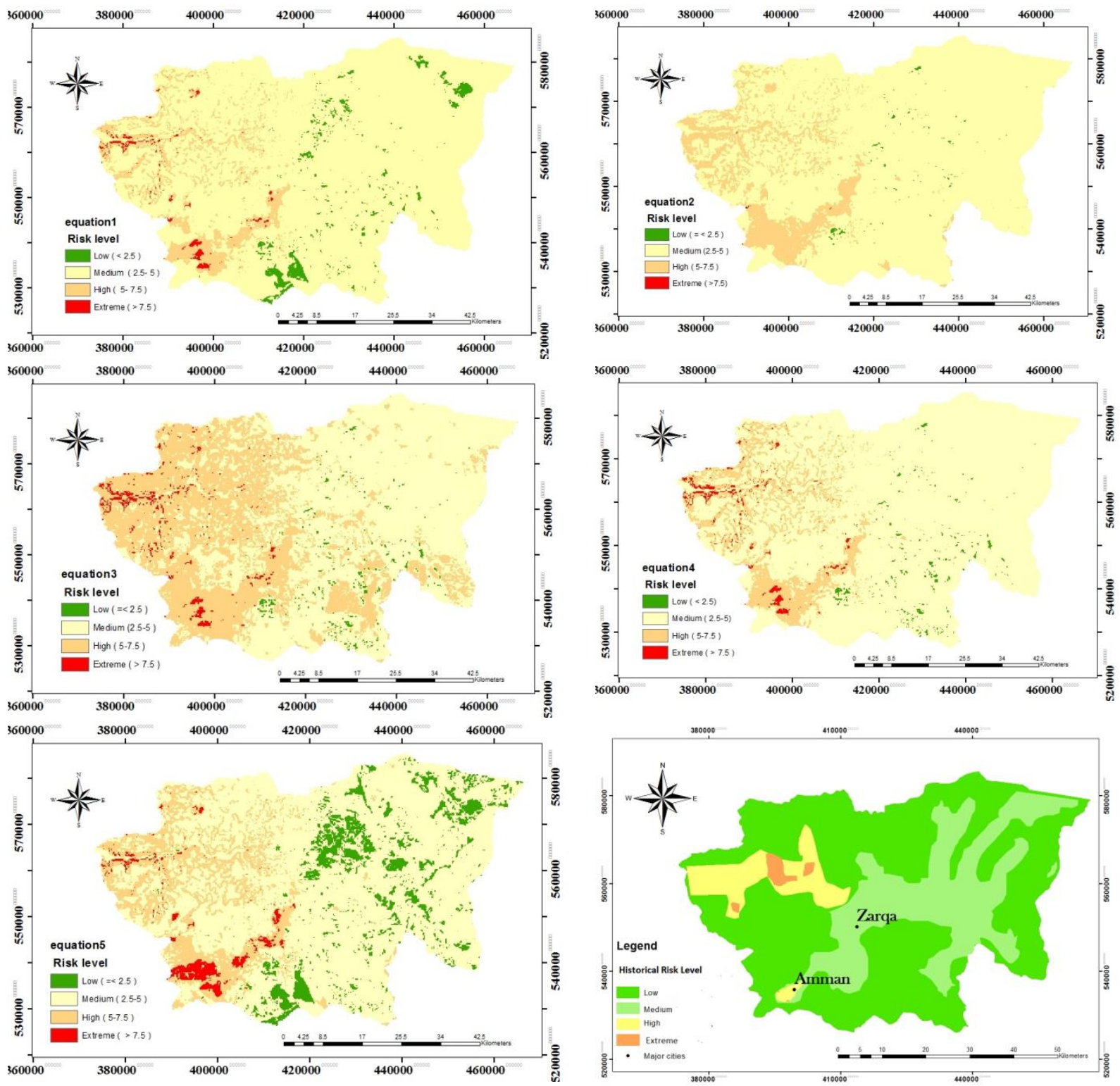

Fig. 14 Risk level map for each scenario compared with historical risk level map for a flash flood. 
Table 7 The percentage of area related to risk level (\%).

\begin{tabular}{|c|c|c|c|c|c|}
\hline Risk Level & Equation 1 & Equation 2 & Equation 3 & Equation 4 & Equation 5 \\
\hline Low & 2.60 & 0.34 & 0.97 & 0.97 & 9.01 \\
\hline Medium & 87.31 & 86.54 & 59.48 & 85.04 & 72.96 \\
\hline High & 9.16 & 13.10 & 38.18 & 12.62 & 15.89 \\
\hline Extreme & 0.93 & 0.02 & 1.37 & 1.37 & 2.14 \\
\hline
\end{tabular}

\section{Conclusions}

The FFPI is an index allowing researchers and decision-makers to detect susceptible places that can produce flash floods. The FFPI has not been applied to any area in Jordan. Four different scenarios are used in this study based on earlier reviews worldwide. In this research, the last scenario is modified based on the Jordanian expert's opinion on the study area's weights (slope, land use/cover, soil texture/type, and vegetation cover/density). Results showed that the slope and land use weights in the used equations were the most influential parameters in this study. The risk level for all scenarios was investigated, and the results showed that most of the study area would be subjected to a medium risk level.

\section{Acknowledgments}

The author would like to thank the Deanship of Scientific Research, Al al-Bayt University for supporting this research.

\section{Nomenclature}

\begin{tabular}{|c|c|}
\hline AHP & $=$ Analytical Hierarchy Process \\
\hline amsl & $=$ Above Mean Sea Level \\
\hline $\mathrm{AZB}$ & $=$ Amman Zarqa Basin \\
\hline bmsl & $=$ Below Mean Sea Level \\
\hline DEM & $=$ Digital Elevation Model \\
\hline FFPI & $=$ Flash Flood Potential Index \\
\hline GIS & $=$ Geographic Information System \\
\hline IUCN & $=$ International Union for Conservation of Nature \\
\hline $\mathrm{L}$ & $=$ Land Cover/Use \\
\hline$M$ & $=$ Slope \\
\hline$n$ & $=$ The weight of the layer \\
\hline$N$ & $=$ Sum of weightings \\
\hline S & $=$ Soil Type/Texture \\
\hline
\end{tabular}

\section{References}

Al Mahamid, J. "Integration of Water Resources of the Upper Aquifer in Amman-Zarqa Basin Based on Mathematical Modeling and GIS, Jordan", Freiberg Online Geology 12, 1-223 (2005).

Al-Momani, A., and Shawaqfah M. "Assessment and Management of Flood Risks at the City of Tabuk, Saudi Arabia", The Holistic Appr. to Envi., 3, 15-31 (2013).

Arachchige D. "Mapping flash flood potential using GIS and the Flash Flood Potential Index (FFPI) in the Turtle River and Forest River watersheds in North Dakota" [dissertation]. The University of North Dakota. 2015.

American Meteorological Society: Glossary of Meteorology, $2^{\text {nd }}$ ed., American Meteorological Society, Boston (2000).

Bender, F.; Geology of Jordan, Gebrueder Borntraeger, Berlin, (1974).

Brewster, J. (2009), "Development of the Flash Flood Potential Index".

Ceru, J. (2012). "Flash Flood Potential Index for Pennsylvania." Proceedings, 2012 ESRI Federal GIS Conference.

Creutin, J., M. Borga, E. Gruntfest, C. Lutoff, D. Zoccatelli, and Ruin I. "A space and time framework for analyzing human anticipation of flash floods", J. of Hydrol. 482, 14-24, (2013).

EM-DAT, Centre for Research on the Epidemiology of Disasters (CRED). (2019, July 25) The International Disaster Database. Retrieved from https://www.emdat.be/

ESRI (2011), ArcGIS Desktop: Release 10. Redlands, CA: Environmental Systems Research Institute.

Fuchs, S. "Susceptibility versus resilience to mountain hazards in Austria-paradigms of vulnerability revisited," Nat. Hazard. Earth. Syst. Sci. 9(2), 337-352 (2019).

Fuchs, S., M. K eiler, and Zischg V. "A spatiotemporal multi hazard exposure assessment based on property data," Nat. Hazard Earth. Syst. Sci., 15(9), 21272142 (2015).

Hammouri, N., Adbulla, F., Abu Qdais, H., and Freiwan, M., "Assessing the impacts of climate change on water resources of Jordan, World Water Congress XV: Climate Change, Impacts and Adaptations, Edinburgh, 25-29 May, 2015.

Howard Humphreys Consulting Engineers Monitoring and evaluation of the Amman-Zarqa Basin aquifers. Amman Water and Sewage Authority, Jordan. (1983). 
Hughey, E. "Hazard response capabilities of a small community: A case study of Falmouth, Kentucky and the 1997 flood", Southeastern geographer, 46, 6678 (2006).

International Union for Conservation of Nature-Regional Office for West Asia (IUCN). (2015). Sustainable Dry land Landscapes Management Mapping Rangeland in Jordan 2015.

International Union for Conservation of Nature (IUCN). (, 2019). Jordan National Disaster Risk Reduction (DRR) Strategy 2019-2022.

IPCC (2014), Summary for policymakers; Climate Change 2014: Impacts, Adaptation, and Vulnerability. Part A: Global and Sectoral Aspects. Contribution of Working Group II to the Fifth Assessment Report of the Intergovernmental Panel on Climate Change.

Karagiorgos, K., T. Thaler, M. Heiser, J. Hubl, and Fuchs S." Integrated flash flood vulnerability assessment: Insights from East Attica", Greece. J. Hydrol, 54, 553-562 (2016a).

Karagiorgos, K., T. Thaler, M. Heiser, J. Hubl, and Fuchs S., "Multi-vulnerability analysis for flash flood risk management", Nat. Hazards, 82, 63-87 (2016b)

Kruzdlo, R. (2010). "Flash Flood Potential Index for the Mount Holly Hydrologic Service 31 Area, Official Site of The State of New Jersey: http://www.state.nj.us/drbc/library/documents/Flood_Website/flood-warning/userforums/ Krudzlo_NWS.pdf.

Mikbel, S., and Zacher W. "Fold structures in Northern Jordan", M. Jb. Palaeont, Mh. H, 4, 248-256 (1986).

Minea, G. "Assessment of the flash flood potential of Basca River Catchment (Romania) based on physiographic factors," Cent. Eur. J. Geosci., 5(3), 344-353 (2013).

MWI, "Guideline for assessment and implementation of Managed Aquifer Recharge (MAR) in (semi-)arid regions. Pre-feasibility study for infiltration of floodwater in the Amman-Zarqa and Azraq basins", (2012)

Pravalie, R. and Costache R. "The analysis of the susceptibility of the flash-floods' genesis in the area of the hydrographical basin of B^asca Chiojdului river", Forum Geografic, 13, 39-49 (2014).

Ruin, I., D. Creutin, S. Anquetin, and Lutoff C. "Human exposure to flash floods - Relation between flood parameters and human vulnerability during a storm of September 2002 in southern France", J. Hydrol., 361, 199-213 (2008).

Saaty, T., The Analytic Hierarchy Process, McGraw-Hill, New York (1980).

Smith G (2003) Flash flood potential: determining the hydrologic response of FFMP basins to heavy rain by analyzing their physiographic characteristics. A white paper available from the NWS Colorado Basin River Forecast Center. Accessed at http://www.cbrfc. noaa.gov/papers/ffp_wpap.pdf

Spitalar, M., J. Gourley, C. Lutoff, E. Kirstetter, , M. Brilly, and Carr N. "Analysis of flash flood parameters and human impacts in the US from 2006 to 2012", J. Hydrol., 519, 863-870 (2014).

Teodor S. and Matreata S. "A way of determining how small river basins of Some's River are susceptible to flash floods," Carpath. J. Earth. Environ., 6, 8998 (2011).

Terti, G., I. Ruin, S. Anquetin, and Gourley J. "Dynamic vulnerability factors for impact-based flash flood prediction", Nat. Hazards, 79, 1481-1497 (2015).

Tobin, G., Theoretical Framework of Flood Induced Changes in Urban Land Values. Water Res. Bul., 22, 67-71 (1986).

USAID and MWI, Characterization of wastewater effluent in the Amman-Zarqa Basin (water reuse component). Water resource policy support activity, plan for managing water reuse in the Amman-Zarqa Basin and the Jordan Valley. United States Agency for International Development (USAID) (2001).

USAID and WAJThe North Jordan water resources investigation project. Amman-Zarqa Basin, Water Authority of Jordan, Amman, Jordan. (1989).

White, G., Flood Hazards in the United States: A Research Assessment. [dissertation]. Institution of Behavioral Science, University of Colorado (1975).

Zaharia, L., R. Costache, R. Pravalie, and Minea G. "Assessment and mapping of flood potential in the Slanic catchment in Romania", J. Earth Syst. Sci., 124, 1311-1324 (2015).

Zogg, J., and Deitsch K., The Flash Flood Potential Index at WFO Des Moines, Iowa. National Weather Service working paper, Iowa (2013) 